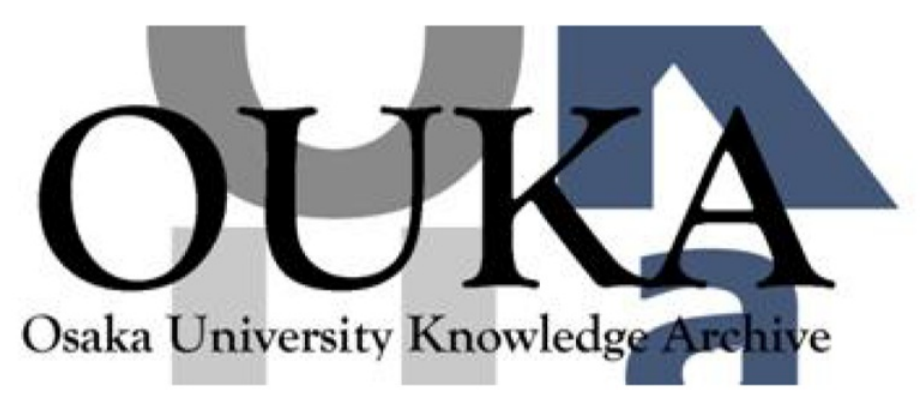

\begin{tabular}{|c|c|}
\hline Title & $\begin{array}{l}\text { A simulation methodology for a system of } \\
\text { product life cycle systems }\end{array}$ \\
\hline Author (s) & $\begin{array}{l}\text { Kobayashi, Hideki; Matsumoto, Takuya; } \\
\text { Fukushige, Shinichi }\end{array}$ \\
\hline Citation & $\begin{array}{l}\text { Advanced Engineering Informatics. } 36 \text { p.101- } \\
\text { p. } 111\end{array}$ \\
\hline Issue Date & $2018-03-20$ \\
\hline oaire:version & AM \\
\hline URL & https://hdl. handle. net/11094/83596 \\
\hline rights & $\begin{array}{l}\text { (- } 2018 \text { Elsevier B.V. This manuscript version is } \\
\text { made avai lable under the Creat ive Commons } \\
\text { Attribut ion-NonCommercial-NoDerivatives } 4.0 \\
\text { International License. }\end{array}$ \\
\hline Note & \\
\hline
\end{tabular}

Osaka University Knowledge Archive : OUKA

https://ir. Library. osaka-u. ac. jp/

0saka University 
Accepted for Publication

\title{
A Simulation Methodology for a System of Product Life Cycle Systems
}

\author{
Hideki Kobayashi*, Takuya Matsumoto, Shinichi Fukushige \\ Department of Mechanical Engineering, Graduate School of Engineering, Osaka \\ University \\ 2-1 Yamada-oka, Suita, Osaka 565-0871, Japan \\ Tel: +81-6-6879-7260 \\ E-mail: kobayashi@mech.eng.osaka-u.ac.jp \\ * Corresponding author
}

\begin{abstract}
To realize environmental sustainability, the flow of natural resources into industrial systems must be reduced and stabilized at a suitable level. One way to reduce resource flows in society is to establish resourcecirculating manufacturing systems. To foster the circulation of resources in industry, life cycle simulation (LCS) technologies, which are based on discrete-event modeling, have been developed to dynamically evaluate the life cycles of products from resource extraction to end of life from both environmental and economic aspects. In reality, various industrial products interact with each other in unanticipated ways, and then these interactions affect the material flows in product life cycles. This type of complex system is called a system of systems (SoS). Focusing on this issue, we expand the evaluation's system boundary to include a system of multiple product life cycle systems. To handle an SoS quantitatively, we introduce typical types of interactions between product life cycle systems. The purpose of this study was to propose a new LCS methodology, called "LCS4SoS," that focuses on an SoS consisting of different kinds of product life cycle systems. A prototype
\end{abstract}


system of LCS4SoS was implemented based on this proposed methodology. Through a case study, it was found that the proposed methodology is useful for evaluating an SoS consisting of multi-product life cycle systems.

\section{Keywords}

Product Lifecycle; Life Cycle Simulation; System of Systems; Discrete-event Simulation, Material Flow

\section{Introduction}

Environmental, social, and economic factors indicate that modern society is not sustainable in its present form [Komiyama and Kraines 2008, Graedel and van der Voet 2010, OECD 2015, Steffen et al. 2015]. Overcoming sustainability issues is a challenge, but doing so is crucial all around the world. For this reason, the United Nations has adopted the Sustainable Development Goals (SDGs) to meet by 2030 which aim to end poverty, protect the planet, and ensure prosperity for all [UN 2015]. From the viewpoint of environmental sustainability, including planetary limits, the situation is worsening [UNEP 2012, Steffen et al. 2015]. For example, global resource extraction and use is accelerating, and the volume of international raw material trade is increasing [UNEP 2016]. To achieve environmental sustainability in terms of not only the improvement of eco-efficiency but also the absolute reduction of environmental impact, absolute sustainability is needed [Hauschild et al. 2017]. One potential effective way of achieving absolute environmental sustainability is to establish resource-circulating manufacturing systems.

A circular economy (CE) is a new economic concept focusing on the improvement of resource performance across the economy. A CE is anticipated as a solution to not only resource depletion but also economic problems such as the creation of jobs and new markets [Ellen MacArthur Foundation 2013]. In line with this concept, the European Commission has adopted a new economic policy called the CE Package to help European businesses and consumers make the transition to a stronger and more circular economy where resources are used in a more sustainable way, such as by sharing, reusing, and recycling products [EC 2015]. The actions taken as part of the CE package are intended to contribute to "closing the loop" of whole product life cycles. Life cycle engineering (LCE) was introduced around a quarter of a century ago in order to address 
environmental sustainability in engineering [Alting and Legarth 1995, Hauschild et al. 2017]. LCE aims to maximize the total profit and reduce the environmental burden through life cycle thinking. Life cycle thinking takes the whole product life cycle into account, including resource extraction, production, usage, and the end of life (EOL) treatment. LCE is vital for achieving a CE.

The evaluation of a product life cycle is a critical factor in LCE. Therefore, methodologies and tools for life cycle assessment (LCA) [ISO 1997, Wenzel et al. 1997] and life cycle simulation (LCS) [Umeda et al. 2000, Takata and Kimura 2003, Kumazawa and Kobayashi 2006] have been developed. A LCA is a methodology for accounting for the input of energy and materials and output of environmental burdens, such as carbon dioxide and water pollutants, statically throughout a product's life cycle. In contrast, LCS is a methodology for dynamic evaluation associated with production plans and collection projections, and is useful for cases of closed-loop manufacturing, including reuse and remanufacturing. Most reported LCA and LCS studies have focused on the life cycle system of an individual product or product family. However, modern engineering systems, including industrial products and social infrastructures, interact with each other in unexpected ways, resulting in increasingly complex systems [Weck et al. 2011]. In such cases, it is desirable to broaden the system boundaries for design and management. The concept of a system of systems (SoS) was proposed to gain understanding of the whole systems that emerge from such dynamic interactions among subsystems [Maier 1996], and various aspects of SoS are being studied [Gorod et al. 2008, Jamshidi 2009]. However, an appropriate evaluation method for such complex systems based on life cycle thinking has not yet been established.

The purpose of this study is to propose a new LCS methodology, called "LCS4SoS," that focuses on an SoS consisting of different kinds of product life cycle systems. In Section 2, related works are reviewed and the issues to be solved are shown. In Section 3, the methodology of LCS4SoS is proposed, consisting of the framework, interaction types, and a simulation procedure. In Section 4, a prototyping system is implemented. In Section 5, a case study is carried out in order to verify the proposed methodology, referring to the example of mobility and battery systems. In Section 6, the significance and remaining issues are discussed, and finally, the paper is concluded in Section 7. 


\section{Related work}

\subsection{Concepts of a resource-circulating manufacturing system}

Some resource-circulating manufacturing systems have already been proposed from an engineering standpoint. Figure 1 shows the concepts of urban mining, industrial symbiosis, and closed-loop manufacturing, three types of resource-circulating manufacturing systems.

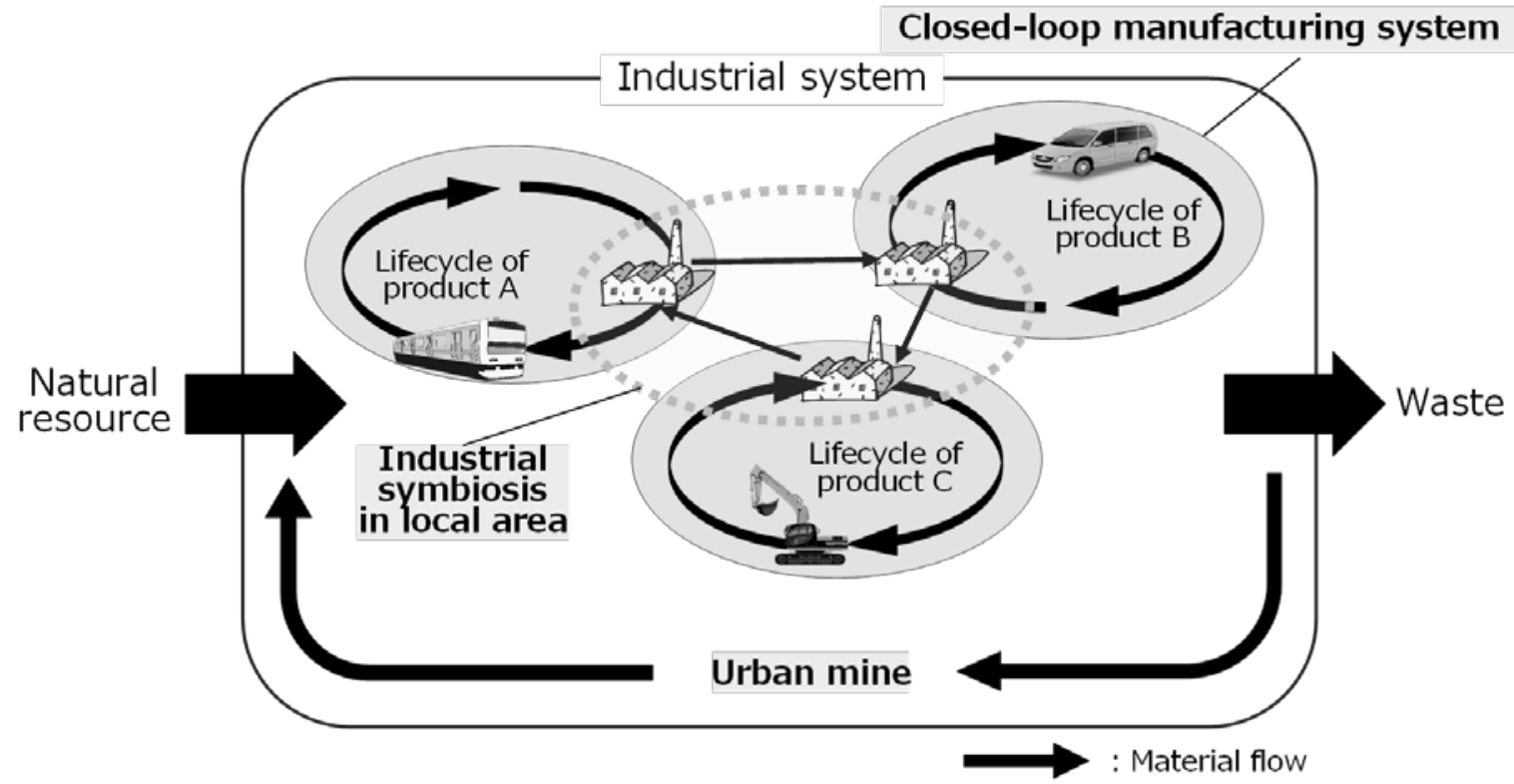

Figure 1: Existing concepts of resource-circulating manufacturing systems

Urban mining may provide an alternative to mining virgin metals [Graedel 2011]. It is based on the concept that a large fraction of metal that is mined flows to cities, while the metal content of the rock being mined continues to decline. Urban mining is the largest-loop material circulation concept in social and economic systems related to the manufacturing industry (Figure 1). However, urban mining has not been achieved because of various unresolved issues. The most difficult problem in urban mining is to establish a total urban mining business model consisting of multiple stakeholders. For instance, it is not clear who will lead the designing and operation of the business system. The private metal refining sector may be one candidate in terms of recycling technology. However, the governmental sector may be also a candidate in terms of national material security. It is also possible that the product manufacturing sector may be a candidate for leading the activity in terms of circular economy. Essentially, the problem is that these stakeholders have their own business models, 
which are basically independent of one another. Therefore, establishing a business model for an urban mining system must be discussed as a long-term, nationwide, multi-stakeholder issue.

Another resource-circulating manufacturing concept that has been proposed is industrial symbiosis [Frosh and Gallopoulos 1989, Chertow 2000, Seendra et al. 2007, Dnmoulin et al. 2016, Velenturf 2016]. Industrial symbiosis is a key concept in industrial ecology that focuses on the exchange of materials, energy, water, and by-products within the business networks in a local area. Many of the tools for industrial symbiosis aim to support the corresponding companies with respect to their input-output compatibility. However, industrial symbiosis does not help improve resource efficiency in terms of the whole product life cycle. It primarily helps in establishing a material network in the production processes of multiproduct life cycle systems for reducing waste emissions out of production systems. Currently, the leading player in industrial symbiosis is the process engineer. Industrial symbiosis is usually carried out under a contract among networked companies, and it takes effect under a constrained area.

Another concept, inverse manufacturing, which was proposed in the mid-1990s, aims to totally optimize a product life cycle and achieve closed-loop manufacturing [Kimura and Suzuki 1996]. The business models of film with lens and photocopier machines are well known as typical real-world examples of closedloop business models. Business models are usually developed by product designers. However, the number of new examples of inverse manufacturing has yet to increase. One reason for this is that it is difficult to control and manage future uncertainty in a closed-loop business. Essentially, a business model of closed-loop manufacturing is profitable throughout collection, reuse, and remanufacturing after the EOL of products. Therefore, product life cycle planning for appropriate life cycle options, such as reuse and remanufacturing, is to be carried out in the early phase of product development [Kobayashi 2006].

If the product market and related technologies have changed significantly from the initial predictions, then the designed life cycle options cannot be executed, resulting in economic and environmental losses. For instance, it is likely that a closed-loop business model for a digital camera planned a decade ago would have failed, because the production volume of digital cameras assumed for reused components would have decreased due to mobile phones and camera functions embedded in smart devices. Furthermore, the product usage intensity and usage period cannot be controlled, resulting in a large amount of uncertainty in the remaining 
lifetime of a collected product or component. Lease and rental services are preferable for reuse businesses because they ensure product collection. Here, a reuse business is defined as a business model in which products are collected and reused [Kumazawa \& Kobayashi 2006]. However, launching a reuse business with a lease or rental service is not easy because the business risks are large [Kobayashi \& Kumazawa 2005]. A supposed closed-loop life cycle scenario is actually changed by interactions between a target-product system and related product systems or new technologies. An additional reason why inverse manufacturing businesses have not increased is because a manufacturing firm generally does not accept business cannibalization, which implies decreasing one's own new product sales by increasing reused or remanufactured product sales [Guide Jr \& Li 2010].

\subsection{System evaluation based on material flow}

The sizes of in-use metal stocks and urban mining stocks are estimated by material flow analysis (MFA) at the national or regional level [Bringezn \& Moriguchi 2002]. MFA utilizes sector-based statistical data on material flow in a country. Therefore, MFA cannot be used for designing and managing an artifact system at the product or business level. In contrast, LCA is used to quantify the environmental burden based on a typical static product life cycle under a given scenario and average material balance [Wenzel et al. 1997]. Setting system boundaries for LCA is one of the crucial points for LCA practice [Tillnvan et al. 1994, Finnveden et al. 2009]. Because it is difficult to collect all of the foreground data of a product life cycle system, minor life cycle processes are actually excluded from the scope of LCA. This is called "cut-off” [Raynolds et al. 2000]. However, a general method for "cut-off" has not yet been achieved. Although traditional LCA may also be called attributional LCA (A-LCA) [Ekvall and Weidema 2004], consequential LCA (C-LCA) has also been proposed with an expanded system boundary for evaluating future scenarios using not only average data but also marginal data [Ekvall \& Weidema 2004]. In a comparative study using A-LCA, one good is replaced directly with an equivalent quantity of another. However, demand substitution and the by-products of a process are also considered in the calculation of C-LCA. In C-LCA, consumption is usually changed indirectly by using an economic behavior model, although there are exceptions. 
LCS [Umeda et al. 2000, Takata \& Kimura 2003, Kumazawa \& Kobayashi 2006] is a method for dynamically estimating environmental load and cash flow based on material flow of a product or parts consisted of a product under long-term product life cycle scenarios at the business level. These calculation principles are based on discrete-event simulation techniques [Zeigler et al 2000] and are carried out by summarizing the total amount of pollutants, waste, energy usage, costs, and profits of a company throughout a certain time period. Various studies on LCS have been conducted, but there are some discrepancies in the definitions of life cycle boundaries with respect to how complex the models should be and what the simulation inputs and outputs should be [Garetti et al. 2012]. Nonetheless, LCS is a powerful tool when the changes in material flow have a large effect on the business performance, such as in reuse businesses. LCS software and tools compute the environmental load and cost for every stage of the product life cycle from material extraction to disposal. The system boundaries of a LCS model are developed by focusing on the target product family. A sharing economy is expected to reduce the total production amount by increasing the usage intensity or operation rate of individual products [Ellen MacArthur Foundation 2013]. By launching a sharing economy, the material input flow into a social system is expected to decrease along with an increasing market share of sharing businesses against traditional ownership businesses. A method to estimate the material flow is yet to be established in the case where sharing and ownership economies are combined.

\subsection{SoS and engineering systems}

SoS is an emerging field of system engineering. A true SoS can be distinguished from large, complex, monolithic systems by the following five principal characteristics [Maier 1996]: operational independence of the elements, managerial independence of the elements, evolutionary development, emergent behavior, and geographic distribution. Gorod et al. have also reported on major features of SoS engineering, such as dynamic boundaries, emergent problems, and continuous timeframes [Gorod et al. 2008]. Because an SoS is a system, it has an objective to achieve, with examples being a national defense system [DoD 2008] or a smart grid system [NIST 2014]. Also, it has been argued that there is a relationship between industrial ecology and SoS. In the study in question [DeLaurentis and Ayyalasomayajula 2009], the necessity of using the merits of SoS and 
industrial ecology to solve sociotechnical problems was shown. However, the management framework of SoS is still under development.

In a similar way, so-called “engineering systems,” or large and complex industrial systems consisting of energy, transport, and communication systems, are gaining focus as a new type of system. These engineering systems are defined as "a class of systems characterized by a high degree of technical complexity, social intricacy, and elaborate processes, aiming at fulfilling important functions in society” [Weck et al. 2011]. Engineering systems have five characteristics [Weck et al. 2011]: they exist in the real world, they are artificial, they have dynamic properties, they have a hybrid state, and they have some human control. Here, hybrid state means that the system has a mixture of both continuous and discrete states. The concept of engineering systems is crucial for designing and operating real artificial systems in terms of externalities inducing unintended consequences and system interactions. As a simple example, increased complexity in automotive system might induce traffic jams that then affect other traffic systems such as the railway and subway systems. Furthermore, the progress of automotive system affects the energy system that supplies fossil fuel and electricity for various types of automobiles, which undergo tremendous technology changes. In this way, the concept of engineering systems is key for dealing with increased scale, scope, and complexity and also with technological change. In order to design and operate engineering systems, life cycle properties of the systems, such as maintainability, are critical. As mentioned above, there are common or similar characteristics between SoS and engineering systems.

To evaluate the dynamic behavior of an SoS or engineering systems, system dynamics (SD) and agentbased modeling (ABM) are applicable. These simulation methodologies were developed for and have been applied to real complex problems such as environmental and economic growth problems. SD was developed by Forrester and others in the 1950s to tackle management problems [Forrester, 2007]. Two types of basic representation of the elements of a SD model are stocks and flows [Richardson, 2011]. A SD model includes the connections and interactions (e.g., feedback loops) among individual elements for simulating the behavior of the entire system. However, SD cannot model individual products as entities that perform depending on the situation because SD is based on given simultaneous equations, in other words, a fixed interaction structure is defined by a system analyst. 
ABM has direct historical roots in complex adaptive systems and the underlying notion that systems are built from the bottom up, in contrast to the top-down systems view taken by SD [Macal and North, 2010]. In ABM, the individuals represented as agents can be any entities that behave somewhat autonomously and interact with other agents. Agents have specialized knowledge for decision-making that they perform themselves. ABM is suited to types of problems in which equations cannot be formulated by a top-down approach. A combination of ABM and LCA has been applied in the field of industrial ecology. For example, $\mathrm{ABM}$ was used for calculating foreground data as input for the LCA of bioelectricity production [Davis et al., 2009]. Therein, an electricity generator was modeled as an agent, and the nonlinear change in power generation technology was modeled within an agent-based model. Florent and Enrico (2015) used ABM to extract data for the vehicle-usage stage and combined it with C-LCA. Although ABM can model a product as an entity at the usage stage, it cannot handle resource circulation such as parts reuse. Because the ABM approach cannot incorporate time delays, it does not track usage history of parts related to individual product life cycle systems.

\subsection{Research issues to be addressed}

As noted in the previous sections, the existing methodologies and tools cannot dynamically evaluate a complex and integrated system consisting of multiple product life cycle systems based on material flows. The point here is that this type of life cycle system integration will be generated unintendedly by interaction among the life cycle processes of different products. This is because the life cycle evaluation period is generally long (i.e., 10-20 years), making it difficult for a system designer or manager to grasp the behavior of future wider engineering systems. Although a system consisting of individual product life cycle systems connected by interactions can be regarded as an SoS, interactions among the systems remain poorly understood and unsystematized from a life-cycle perspective. The above research issues are essential in the design and management of complex product life cycle systems with regard to reducing material input flow at the industry level.

\section{Methodology of LCS4SoS}

\subsection{Framework for dynamic evaluation of an SoS}


This study focuses on a system consisting of PLC systems. This system is regarded as an SoS by introducing interactions with the material or information flow among individual PLC systems (Figure 2). The LCS4SoS is for the dynamic evaluation of an SoS in terms of material flows. By using the LCS4SoS, the difference between the total natural resource input flow of the target SoS and that of simple aggregation of individual PLC systems can be calculated.

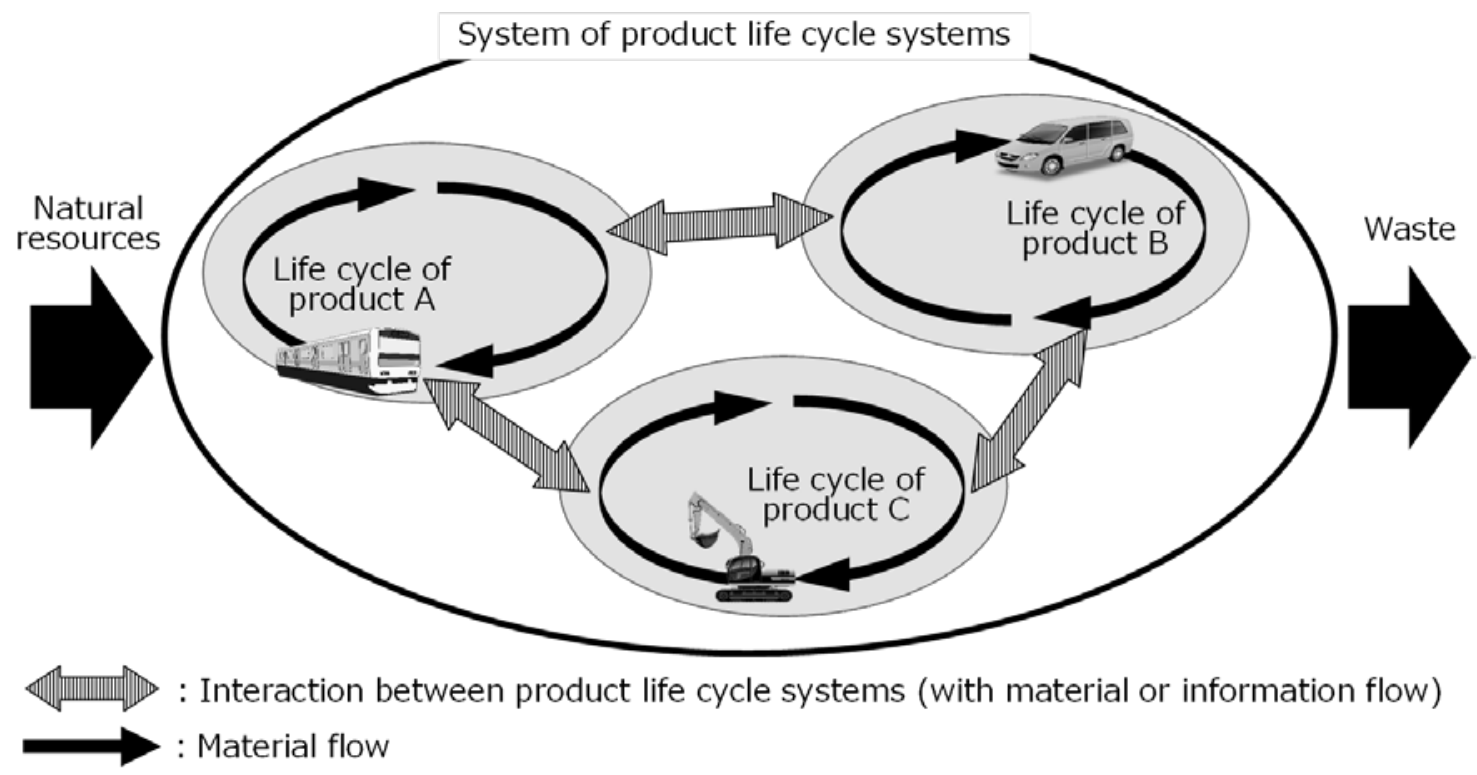

Figure 2: An SoS consisting of individual product life cycle systems

The framework consists of three elements, namely, individual product life cycle systems, interactions between them, and their evolution over time. As an explanation of this framework, Figure 3 shows a schematic of the evolution of interactions among product life cycle systems. In Figure 3, each circle indicates an individual product life cycle system. The dashed line indicates the overall evaluation boundary, including the multiple product life cycle systems to be considered. In this study, "overall evaluation boundary” is defined as an aggregation of the system boundaries of the target product life cycle systems and their related life cycle systems. We make the following assumptions: (i) the overall evaluation boundary is given by an engineering analyst, (ii) it does not change in one simulation scenario, and (iii) it is possible to include multiple SoS boundaries in the overall evaluation boundary. In most cases, the 
individual product life cycle systems are designed, launched, and managed independently $(t=0)$. Industrial products in the use phase are regarded as in-use stock in this study. Next, interactions among the life cycle systems appear, and an SoS consisting of these systems is generated $(t=1,2)$. If the interactions disappear, the SoS also disappears. Thus, the boundary of the SoS changes dynamically. The total resource inflow to the overall evaluation boundary does not necessarily decrease at any time. Whether the interactions decrease the inflow of virgin resources or not is also evaluated.

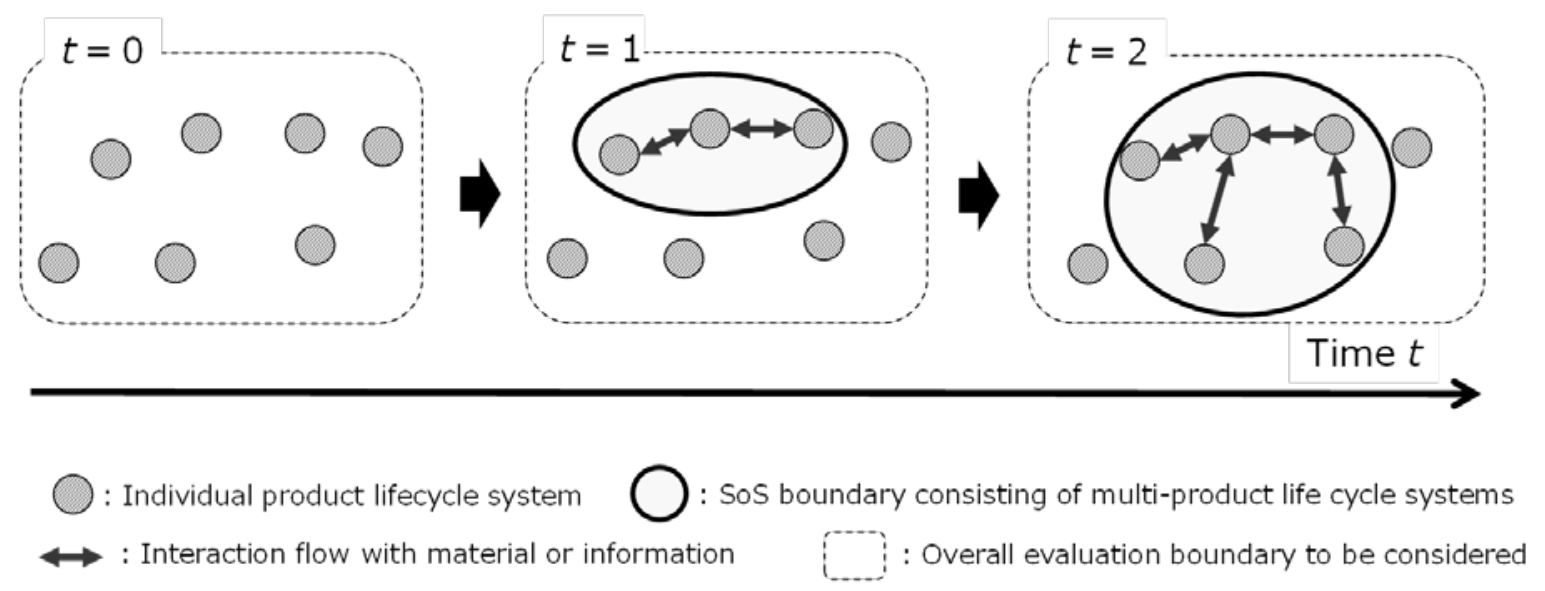

Figure 3: Time evolution of interactions among product life cycle systems

In the proposed framework, interactions among product life cycle systems are categorized into the following five categories and eight types (Figure 4 and Table 1). The basic idea of interaction among product life cycle systems was proposed by Kobayashi (2016) and is extended here. We propose the interactions based on our knowledge of LCE and industrial ecology; these are key aspects of the present study. The idea of demand substitution comes from C-LCA [Ekvall and Weidema, 2004], and the idea of reuse of factory waste comes from industrial symbiosis [Dnmoulin et al., 2016; Chertow, 2000; Velenturf, 2016; Frosh and Gallopoulos, 1989; Seendra et al., 2007]. The other ideas, such as global reuse and demand increase by sub-function, come from life-cycle planning (LCP) methodology [Kobayashi, 2003]. 


\section{SoS consisting of product life cycle systems}

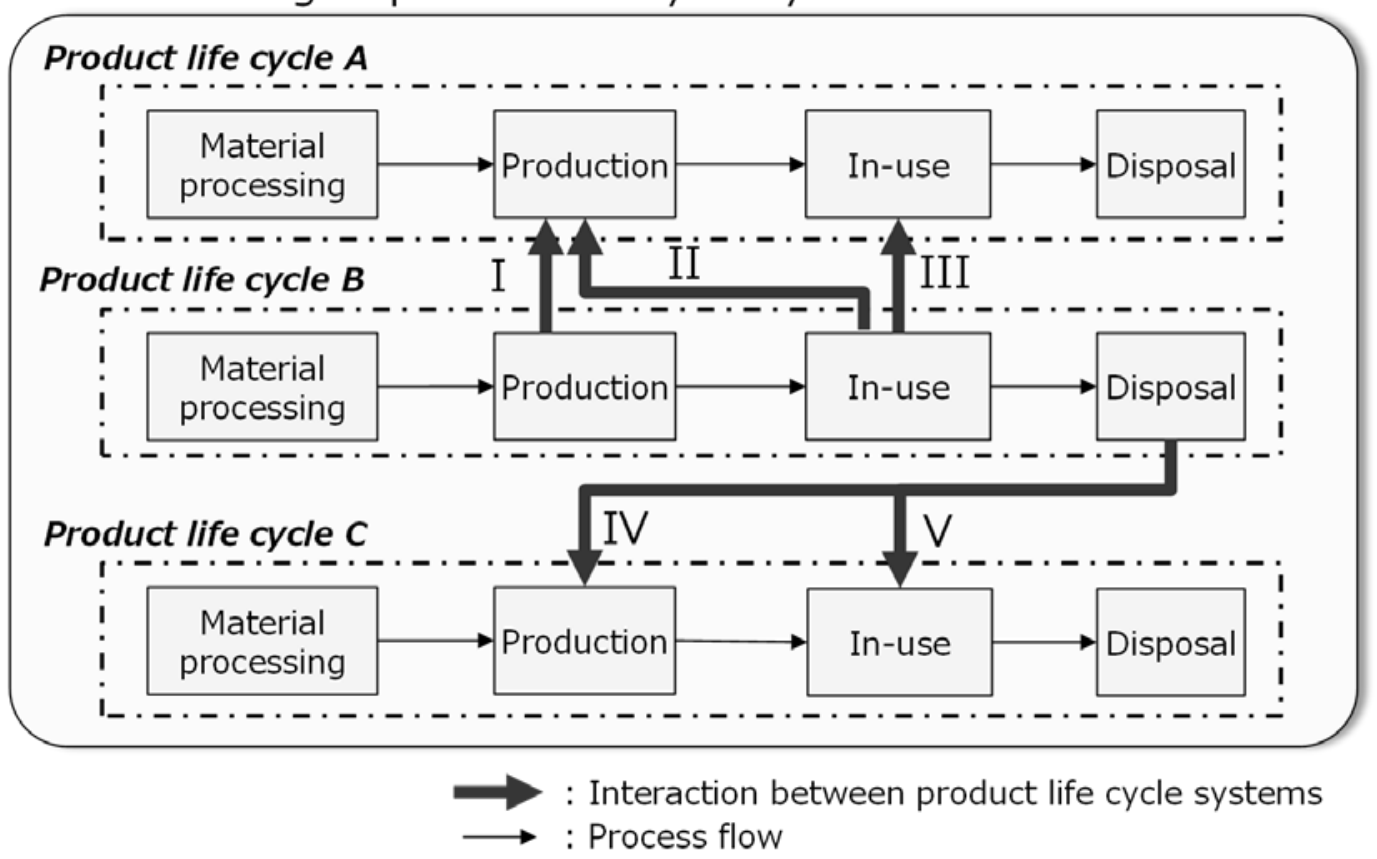

Figure 4: Schematic of typical interactions among product life cycle systems

Table 1: Eight types of interaction among product life cycle systems

\begin{tabular}{|c|c|l|}
\hline Category & Type & \multicolumn{1}{|c|}{ Content } \\
\hline \multirow{2}{*}{ I } & I-a & Demand substitution with an alternative product (information flow) \\
\cline { 2 - 3 } & I-b & Demand increase by diffusion of a related product (information flow) \\
\cline { 2 - 3 } & I-c & $\begin{array}{l}\text { Reuse of factory waste as a resource for other product life cycle process } \\
\text { (material flow) }\end{array}$ \\
\hline \multirow{2}{*}{ II } & II-a & Demand substitution by sub-function (information flow) \\
\cline { 2 - 3 } & II-b & Demand increase by sub-function (information flow) \\
\hline III & III-a & Substitution of usage intensity of in-use stock (information flow) \\
\hline V & IV-a & $\begin{array}{l}\text { Global reuse of old products in different new or like-new products (material } \\
\text { flow) }\end{array}$ \\
\hline
\end{tabular}

The first type is a demand substitution with an alternative product, or in other words, a configuration change of the in-use stock (I-a in Table 1). This implies that the sales or production of product A depends on 
the demand for product B (Figure 4). This type of interaction is relevant when the total market capacity is a constraint and the product share is the only business consideration. This interaction emerges between competing products, for example, between gasoline vehicles (GV) and electric vehicles (EVs). The second type is a demand increase by diffusion of a related product, or in other words, the synergy effect of sales (I-b in Table 1). This interaction emerges between products in the same business ecosystem. For example, the ion generator and its embedded equipment, such as air-conditioners and vacuum cleaners, diffuse by the synergy effect. Moreover, the diffusion of new products based on a new industrial standard increases the demand for other related products based on the same standard. The third type is the reuse of production waste from one company as a resource for another company's product life cycle process, such as in other production processes (I-c in Table 1). This is regarded as a typical material flow for industrial symbiosis.

The fourth type is demand substitution by sub-function (II-a in Table 1). This means that the sales or production of product A depends on the usage of the sub-function of product B. For a high-grade multifunctional product, the sub-function itself sometimes affects other product sales. For instance, personal computers with high-quality displays may decrease sales of televisions for single households. The fifth type is a demand increase by sub-function (II-b in Table 1). As in type I-b, a kind of synergy effect occurs due to the sub-function of an in-use product. For instance, because the functional quality of digital cameras in smart phones may have become too high and generalized for ordinary people, unfashionable products such as film with lens may become popular again in specific markets in Japan.

The sixth type is the substitution of usage intensity of in-use stock (III-a in Table 1). This means that the operation mode of product A depends on the use of the sub-function of product B (Figure 4). For example, a multifunctional product, such as a mobile information device, may decrease the operation time of other information devices, such as internet televisions. This type of substitution of usage intensity may have diversified fluctuations depending on the type of business use or the lifestyle of a product user.

The seventh type is global reuse as other new or like-new products (IV-a in Table 1). Here, global reuse means that a used component or module is reused in a different kind of product. A general purpose component could be used this way when it has a long remaining lifetime. Global reuse is a well-known life cycle option, but it has not been analyzed in depth. The last type is global reuse for spare parts to prolong the 
lifetime of in-use stock (V-a in Table 1). For example, a component from product B at its EOL is reused for the maintenance of product C. In the context of the stock-based approach, this type of interaction is important for solving the problem of component suppliers discontinuing components (Figure 4).

The global reuse of components (types IV-a and V-a) is defined as a material flow not in one particular product life cycle system but in inter-product life cycle systems. Therefore, global reuse is considered an interaction for an SoS in this study.

It should be noted that the start and end processes of an interaction can actually change slightly, because they depend on whether the target production system is based on a push-system, such as material resource planning, or a pull-system, such as just-in-time or the Kanban System [Benton and Shin 1998]. If the target production system is modeled as a push-system, then the end point of the types I-a, I-b, and II-a interactions is the sales process, because products in stock exist. On the other hand, in the case of a pull-system, the amount of production is affected directly by the interaction. Figure 4 shows a simplified schematic of typical interactions.

\subsection{Simulation procedure}

Figure 5 shows the procedure for LCS4SoS. In step (a), specific products are selected as target products by an engineering analyst. This means setting the overall evaluation boundary. For instance, a target product life cycle system of high interest is selected depending on the purpose. Then, related product life cycle systems are selected from technological and business aspects that interact obviously and potentially. Here, the main objective of the simulation is to quantify the input flow of the natural resources to an evaluation boundary for the targeted product life cycle systems in order to reduce and stabilize the input resource flow. In step (b), data from the target product life cycle systems, such as the bill of materials (BOMs) of target products, input energy, and indirect materials, is collected, and the life cycle models of the selected products are preliminarily established on the basis of traditional LCS methodologies. In this step, precise data for the life cycle process is not needed, because the data is used for the preliminary simulation in step (d). In step (c), an engineering analyst sets the interactions among the life cycle processes of different products. Here, the engineering analyst sets an interaction based on future research, for example new technology prediction and socioeconomic policies related 
to sustainable consumption and production (SCP) such as EU's CE Package. Then she or he selects its type of interaction from the eight types described in Section 3.1. At this time, an SoS boundary is set tentatively by arranging product life cycle systems with interactions.

In step (d), the preliminary calculations for the selected life cycle models are executed. Here, a tentative SoS boundary is used. The simulation model consists of an SoS and individual life cycle models that are outside of the SoS are included in the same evaluation boundary. In step (e), an engineering analyst assesses whether the SoS configuration and evaluation boundary are appropriate by using appropriate evaluation indicators. If they are appropriate, then more precise data in the evaluation boundary is collected. Then, the calculation is executed using the complete LCS4SoS model in step (f). If not appropriate, the engineering analyst adjusts the system boundary and the interaction type and its connection. In this study, setting the interactions between the product life cycle systems and the SoS boundary is crucial to the output of LCS4SoS. Then, various settings for the SoS boundary and interactions are verified by using an index of high interest for each case, such as a specific base metal consumption. Since the behavior of the material flow is complex when considering the interactions among different kinds of product life cycle systems, the empirical cut-off method for the system boundary is not appropriate. Therefore, considering the boundary of the SoS and the interactions involved it is a key process.

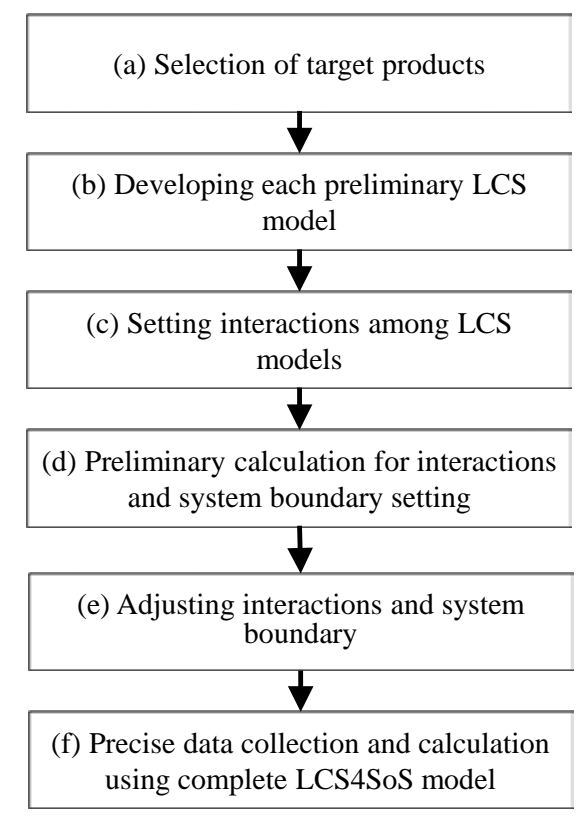

Figure 5: Evaluation procedure of LCS4SoS 


\section{System implementation}

A prototype system for LCS4SoS has been developed in order to execute the proposed evaluation procedure. The configuration of this prototype system for LCS4SoS is shown in Figure 6. The system consists of system interfaces, databases, the LCS4SoS model manager, and the simulation engine. An engineering analyst accesses the database editor to make primitive data. Data about the parts configuration of a product, the BOM of parts, and so on is stored in the product database. Manufacturing data, product usage, the EOL of a product, and waste treatment are stored in the process database. The embodied intensity data such as electricity, the unit material, the unit process, and so on are stored in the LCA database. Next, the engineering analyst configures a LCS model for a single product or product family using primitive databases via the LCS model editor. Then, the engineering analyst sets the interactions among the LCS models and the boundary of the SoS on the LCS4SoS model manager via the SoS model. The overall evaluation boundary and conditions of the simulation are set in the same way. The results of the editing are loaded onto the simulation engine, and then the calculations for the selected life cycle models are executed. The results of the calculations are visualized by the visualizer.

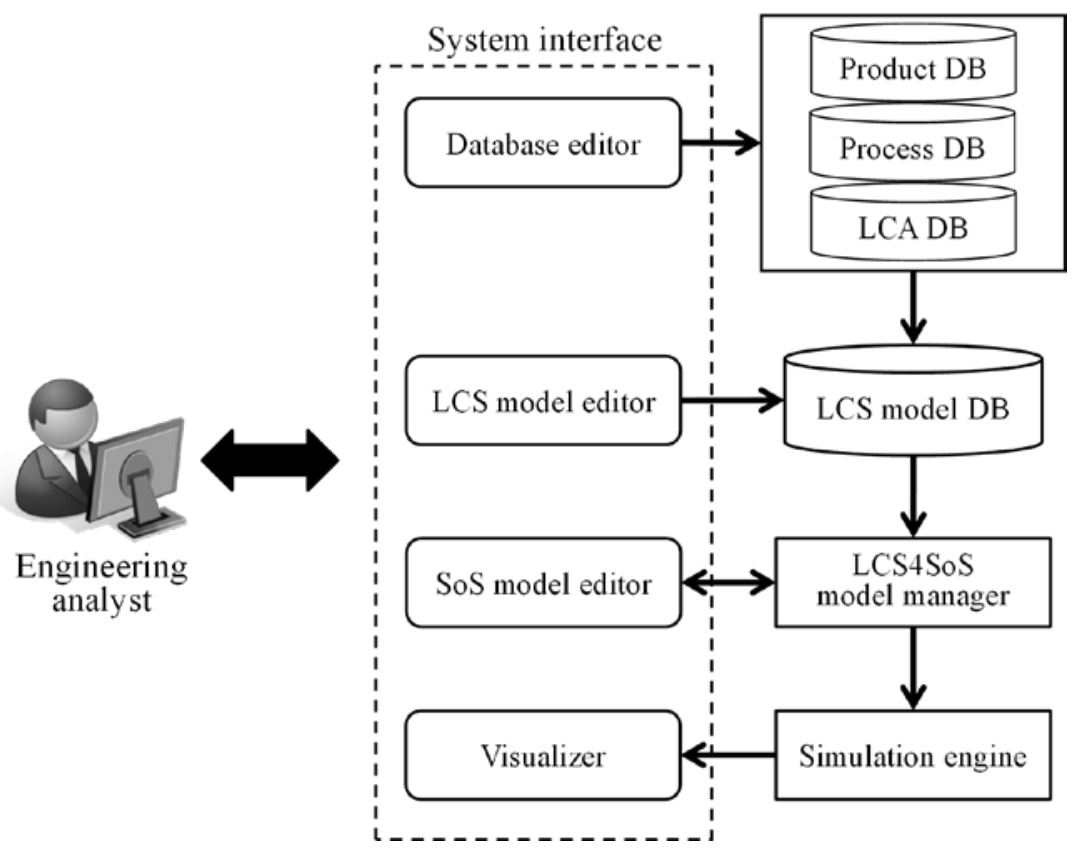

Figure 6: The system configuration of a prototype system of LCS4SoS 


\section{Case study}

In this section, a case study is carried out according to the evaluation procedure steps shown in Section 3.2. The purpose of this case study is to show the computability of the material inflow of an SoS consisting of product life cycle systems at the industry level rather than the company level. In this paper, it is assumed that one kind of product is produced by only one product manufacturer.

STEP (a): First, an EV is selected as a target product. It is related to various other kinds of products and technology, for example, hybrid vehicles (HVs), EVs, battery charge stations (BCSs), GVs, home photovoltaic (PV) systems, and home battery (HB) systems.

STEP (b): Next, rough LCS models were developed. Table 2 shows the specifications of the products modeled.

Table 2: Specification of the initial target products

\begin{tabular}{|l|l|l|}
\hline Product & Specification & Data source \\
\hline Gasoline vehicles (GVs) & 1,500-cc internal combustion engine equivalent. & [NEDO 2008] \\
\hline Hybrid vehicles (HVs) & Corresponsive as above. & [NEDO 2008] \\
\hline Electric vehicles (EVs) & $\begin{array}{l}\text { Corresponsive as above. Energy density of battery: } \\
\text { 100Wh/kg. Energy efficiency of EV: 10km/kWh. }\end{array}$ & [NEDO 2008] \\
\hline Home battery (HB) systems & Power storage capacity: 6 kWh/household & [NEDO 2008] \\
\hline $\begin{array}{l}\text { Home photovoltaic (PV) } \\
\text { systems }\end{array}$ & Poly-Si type PV cell. Power output: 3.9 kW & [NEDO 2009] \\
\hline Battery charge station (BCS) & Output: $50 \mathrm{~kW}$ DC 400 V, 100 A & $\begin{array}{l}\text { [CHAdeMO 2010, } \\
\text { 2017] }\end{array}$ \\
\hline
\end{tabular}

Here, the evolution over time of the product diffusion of the target products is given in Figure 7, where the vertical and horizontal axes represent the amount of in-use stock and the time, respectively. The calculation period is 20 years, from 2015 to 2035. The amount of product diffusion for EVs, HVs, and PVs was estimated based on the logistic curve model [Bass 1969] shown in Eq. (1), assuming that the area had 180,000 households. The constants used in the estimation are listed in Table 3. The amount of in-use stock of GVs was calculated as the difference between the amount of total automobile diffusion of GVs and those of EVs and HVs. The amount of HB systems was calculated by doing a nationwide prediction using the ratio of household numbers in the 
period of 2015 to 2020 and the rate of increase in HVs in the period 2020 to 2035. The value for BCSs was set as one-sixth that of EVs.

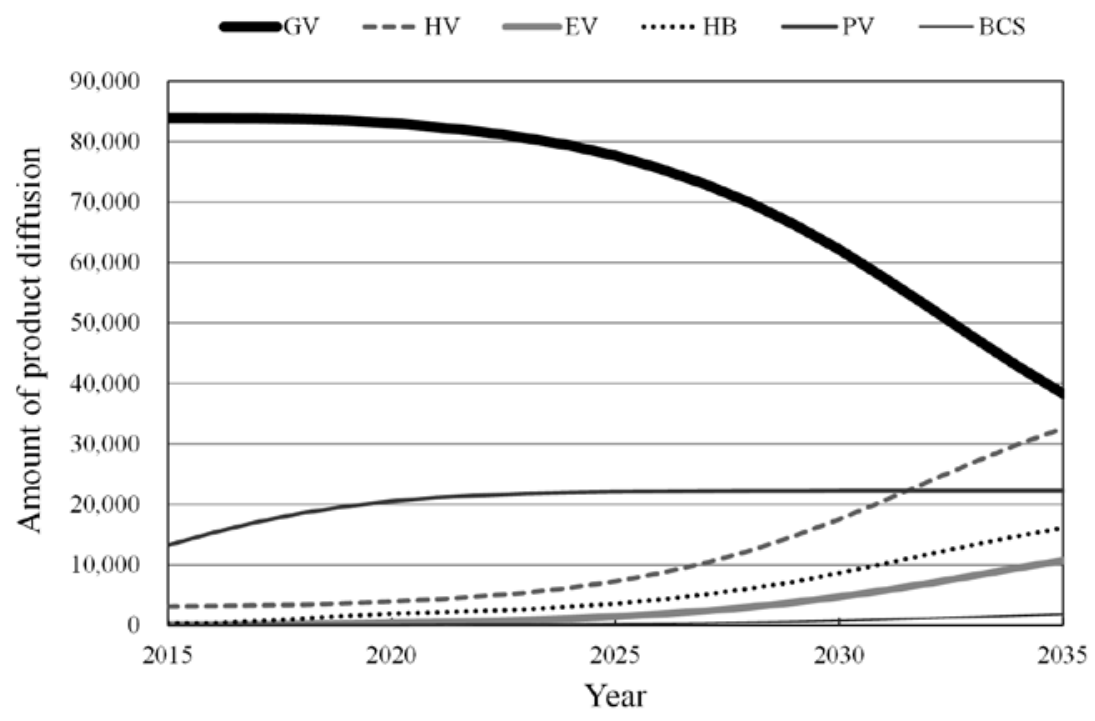

Figure 7: Assumed data for product diffusion

$$
X(t)=(p+r \cdot n(t)) \cdot(1-n(t)) \cdot N,
$$

where $p$ is the innovation coefficient, $r$ is the imitation coefficient, $N$ is the amount of final product diffusion, $X(t)$ is the amount of product diffusion at $t, n(t)$ is the diffusion ratio of a product at $t$, and $t$ is the month.

Table 3: Input data for Eq. (1)

\begin{tabular}{|c|c|c|c|}
\hline \multirow{2}{*}{ Constant } & \multicolumn{3}{|c|}{ Product } \\
\cline { 2 - 4 } & EV & HV & PV \\
\hline$N\left(10^{6}\right)$ & 16.0 & 39.0 & 22.3 \\
\hline$p\left(10^{-4}\right)$ & 3.95 & 4.28 & 233 \\
\hline$R$ & 0.550 & 0.380 & 0.341 \\
\hline
\end{tabular}

STEP (c): In an initial LCS model of an SoS, interactions among the LCS models were set as shown in Figure 8 and Table 4. For instance, the interactions (7) and (2) in Figure 8 decrease the EV battery lifetime and the sales of HB systems, respectively, because an EV owner also uses it as an alternative HB system. 
(3)

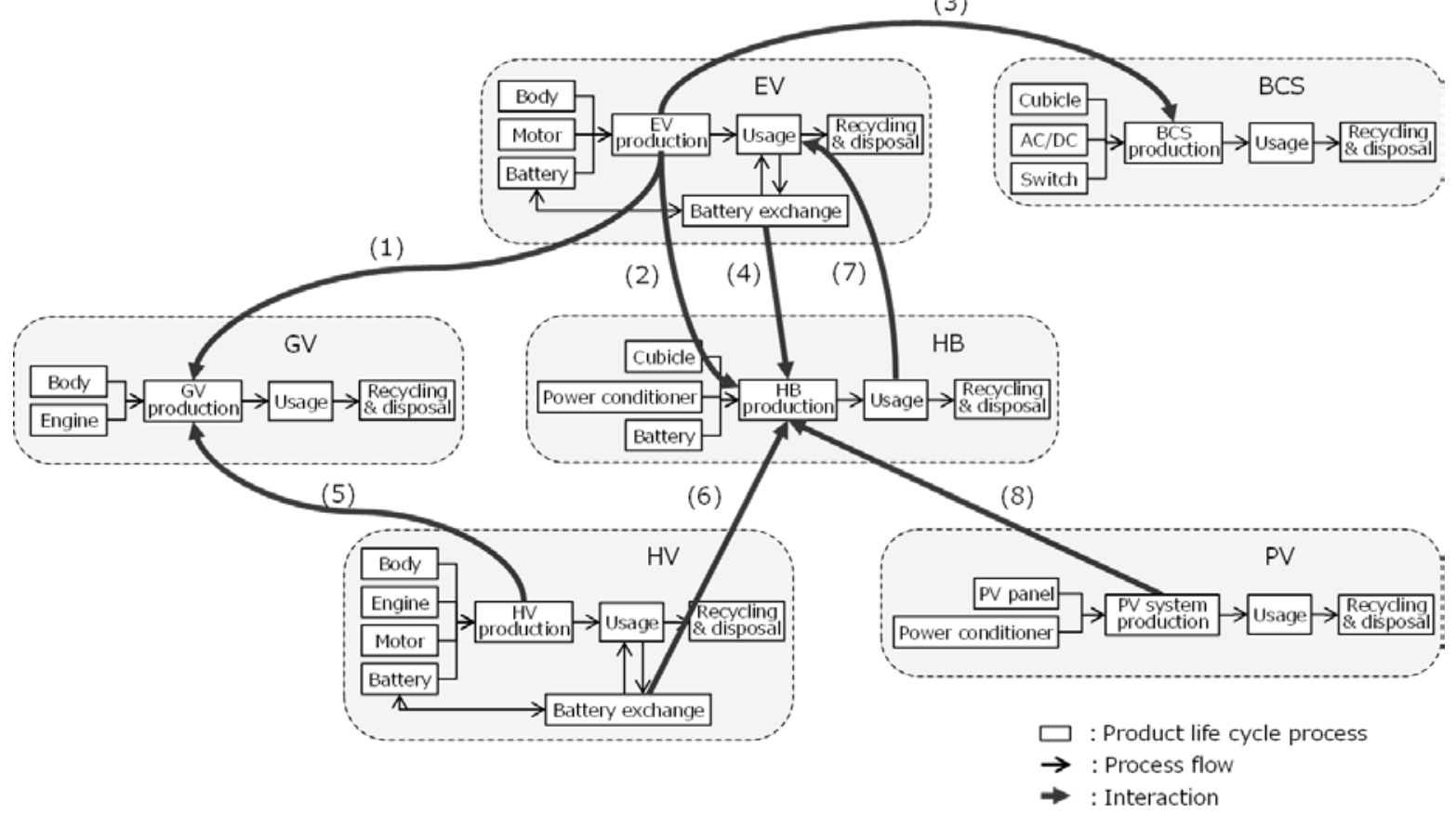

Figure 8: Initial LCS4SoS model with interactions among LCS models

Table 4: Interactions used in Figure 8

\begin{tabular}{|c|l|l|c|l|}
\hline $\begin{array}{c}\text { Interaction } \\
\text { ID } \\
\text { number }\end{array}$ & $\begin{array}{l}\text { Beginning } \\
\text { process of } \\
\text { interaction }\end{array}$ & $\begin{array}{c}\text { End process of } \\
\text { interaction }\end{array}$ & $\begin{array}{c}\text { Type of } \\
\text { interaction }\end{array}$ & Content of interaction \\
\hline$(1)$ & $\begin{array}{l}\text { Production of } \\
\text { EVs }\end{array}$ & Production of GVs & I-a & Replacing GVs with EVs \\
\hline$(2)$ & $\begin{array}{l}\text { Production of } \\
\text { EVs }\end{array}$ & Production of HBs & II-a & Using EVs as a substitute for HBs \\
\hline$(3)$ & $\begin{array}{l}\text { Production of } \\
\text { EVs }\end{array}$ & $\begin{array}{l}\text { Production of } \\
\text { PCSs }\end{array}$ & I-b & Diffusion of BCS with diffusion of EV \\
\hline$(4)$ & $\begin{array}{l}\text { Exchange of } \\
\text { EV batteries }\end{array}$ & Production of HBs & IV-a & Global reuse of battery of EV \\
\hline$(5)$ & $\begin{array}{l}\text { Production of } \\
\text { HVs }\end{array}$ & Production of GVs & I-a & Replacing GV with HV \\
\hline$(6)$ & $\begin{array}{l}\text { Battery } \\
\text { exchange of } \\
\text { HVs }\end{array}$ & Production of HBs & IV-a & Global reuse of battery of HV \\
\hline$(7)$ & $\begin{array}{l}\text { Usage of HBs } \\
\text { t( })\end{array}$ & $\begin{array}{l}\text { Usage of EVs } \\
\text { PVs }\end{array}$ & III-a & $\begin{array}{l}\text { Increasing usage intensity of EV battery } \\
\text { by adding usage as HB system }\end{array}$ \\
\hline
\end{tabular}


STEP (d) and (e): A preliminary simulation was carried out. The simulation period was 20 years, from 2015 to 2030. Here, the production adjustments caused by interactions (1), (2), and (5) were not calculated endogenously but were given exogenously using the data shown in Figure 7. We focused on the copper consumption because copper scarcity is predicted for several decades [Kishita et al. 2012]. Table 5 shows that the cumulative weights of virgin copper consumption for the product life cycle systems of PVs, HBs, and BCSs are smaller than those of EVs, HVs, and GVs. In this study, the cut-off factor, which means omitting materials or components that have little effect on the final environmental impact, was set to $1 \%$ by weight. Then, the final SoS boundary was set, omitting the life cycle systems of PVs and BCSs, as shown in Figure 9. In this case, the SoS boundary is the same as the overall evaluation boundary.

Table 5: Cumulative virgin copper consumption during the simulation period

\begin{tabular}{|c|c|c|c|c|c|c|c|}
\hline Target product & GV & HV & EV & HB & PV & BCS & Total \\
\hline $\begin{array}{c}\text { Cumulative copper input } \\
{[\mathrm{kg}]}\end{array}$ & 173,685 & 123,904 & 528,195 & 14,400 & 5,640 & 2,209 & 848,033 \\
\hline $\begin{array}{c}\text { Weight \% to total amount } \\
{[\%]}\end{array}$ & 20.5 & 14.7 & 62.6 & 1.2 & 0.7 & 0.3 & 100 \\
\hline
\end{tabular}

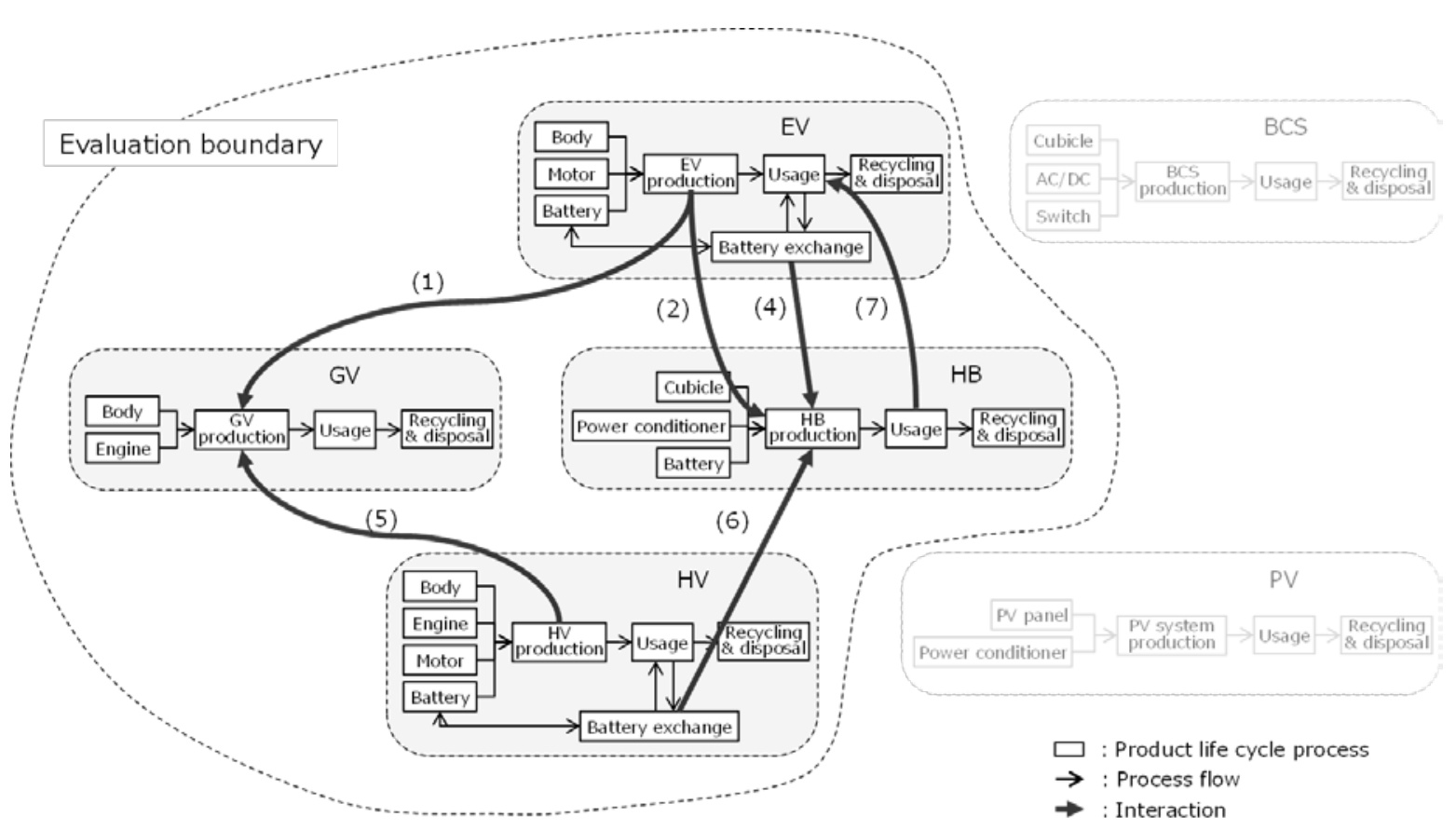

Figure 9: Final LCS4SoS model 
STEP (f): The complete data collection and simulation were carried out based on the final boundary information. The simulation scenarios are given in Table 6. The difference between scenarios “-I” and “-II” depends on whether advances in battery performance, namely, improvements in the energy density of EV batteries, is taken into account. The usage ratio of EV battery as HB in LCS4SoS-I and -II scenarios is $20 \%$ fixed during calculation period. Here, the amounts of product diffusion of HB of LCS4SoS-I and -II are given as shown in Figure 7. On the other hand, those of LCS-I and -II scenarios are adjusted under the condition that no-interaction exists between EV and HB.

Table 6: Simulation scenarios

\begin{tabular}{|l|l|l|}
\hline \multicolumn{1}{|c|}{$\begin{array}{c}\text { Name of } \\
\text { scenario }\end{array}$} & \multicolumn{1}{|c|}{ Calculation method } & \multicolumn{1}{c|}{ Energy density of EV batteries } \\
\hline LCS-I & Simple aggregation of LCS outputs & $100 \mathrm{Wh} / \mathrm{kg}$, fixed during calculation period \\
\hline LCS4SoS-I & LCS4SoS & As above \\
\hline LCS-II & Simple aggregation of LCS outputs & $\begin{array}{l}\text { Increased linearly from } 100 \mathrm{Wh} / \mathrm{kg} \text { in } 2015 \text { to } \\
400 \mathrm{Wh} / \mathrm{kg} \text { in } 2035\end{array}$ \\
\hline LCS4SoS-II & LCS4SoS & As above \\
\hline
\end{tabular}

Figure 10 shows the monthly consumption of virgin copper calculated by LCS4SoS and by simple aggregation of the individual LCS outputs. Figure 11 shows a comparison in the final month. As shown in Figures 10 and 11, the results differ depending on whether the LCS models interact. The LCS4SoS-II output indicates the lowest copper consumption because the energy density of an EV battery progresses year by year but an HB improves more in terms of cost efficiency than performance. Therefore, copper consumption decreases as EV batteries are used more as full substitutes for HBs totally, although the degradation of EV batteries is accelerated by their alternative use as HB systems, leading to more EV batteries being produced. However, the interactions cause a negative environmental effect, namely an increase in overall copper consumption in the case of the LCS4SoS-I scenario. This is because the effect of more EV batteries being produced because of their alternative use as HB systems is more pronounced than the effect of copper consumption decreasing because of a drop in HB system sales (Figure 11). 


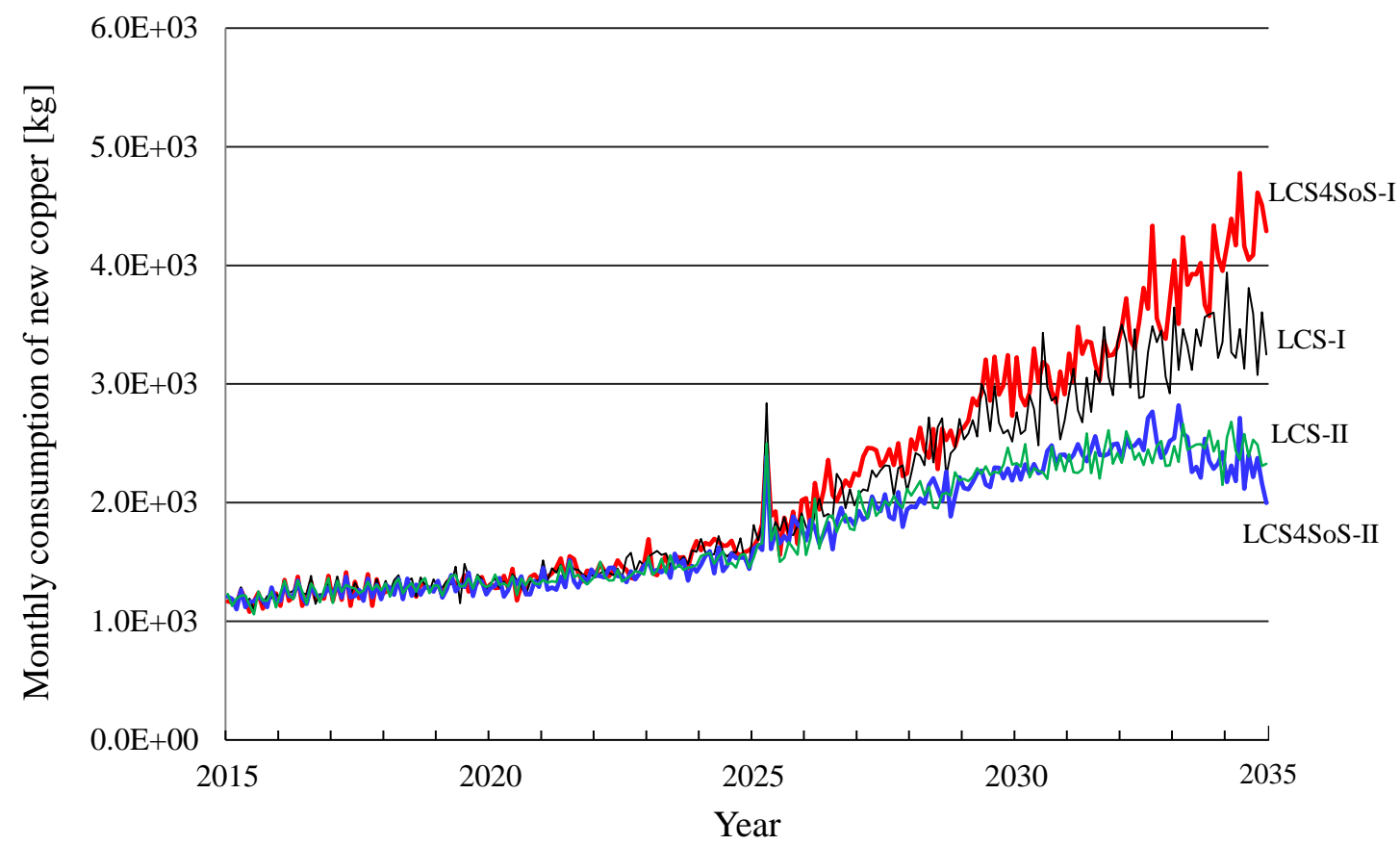

Figure 10: Comparison of virgin copper consumption between LCS4SoS and a simple aggregation of LCS outputs with the same overall evaluation boundary

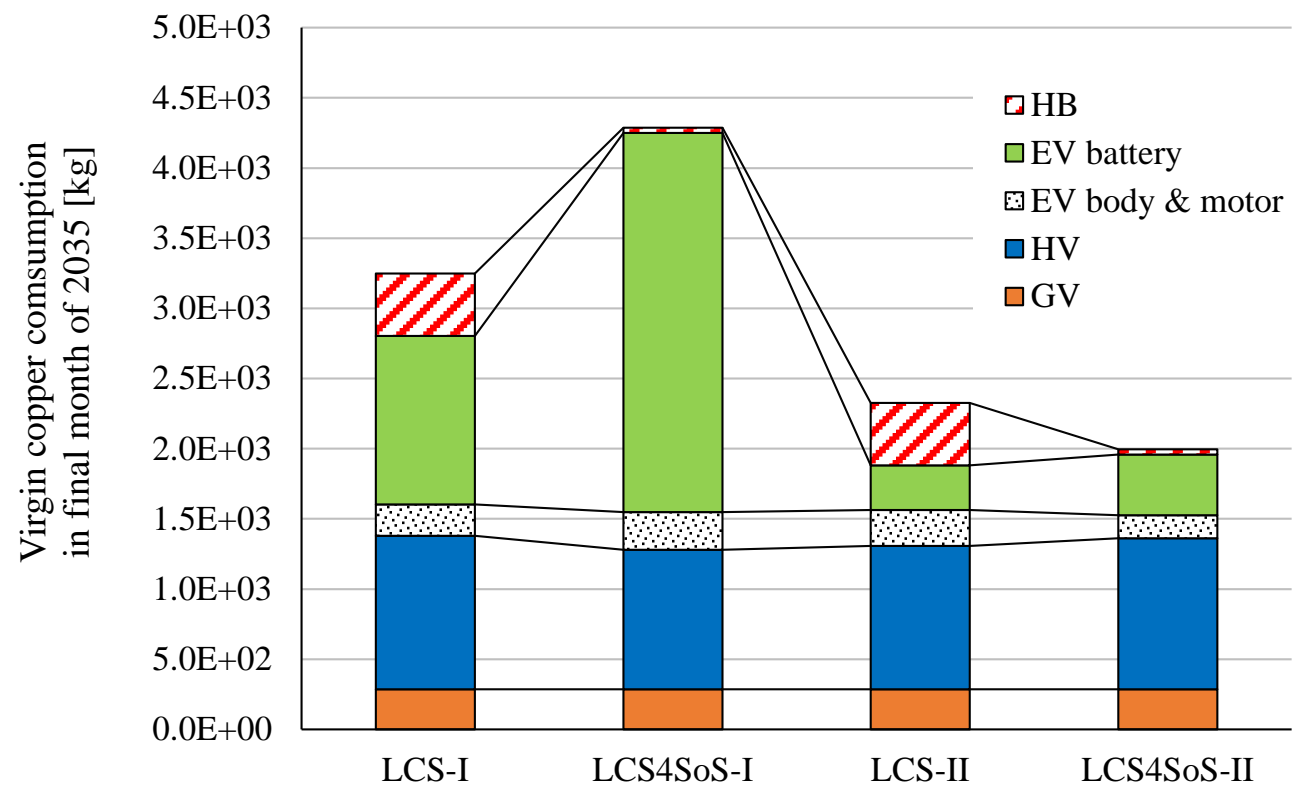

Figure 11: Comparison between LCS4SoS and a simple aggregation of LCS outputs in the final month 
Figure 12 shows the monthly carbon dioxide emissions calculated by LCS4SoS and the simple aggregation of individual LCS. Due to the demand decrease for GVs and demand increase for HVs and EVs, the total system emissions of carbon dioxide decreased in all results. The reduction in carbon dioxide emissions is greatest in the LCS4SoS-II scenario, whereas the environmental gain of the LCS4SoS-I scenario is less than that of the independent product life cycle systems (LCS-I). The reason for the differences among the simulation scenarios is the same as in the case of copper consumption, namely it depends on the progress of EV battery performance and the alternative use of EV batteries as HB systems.

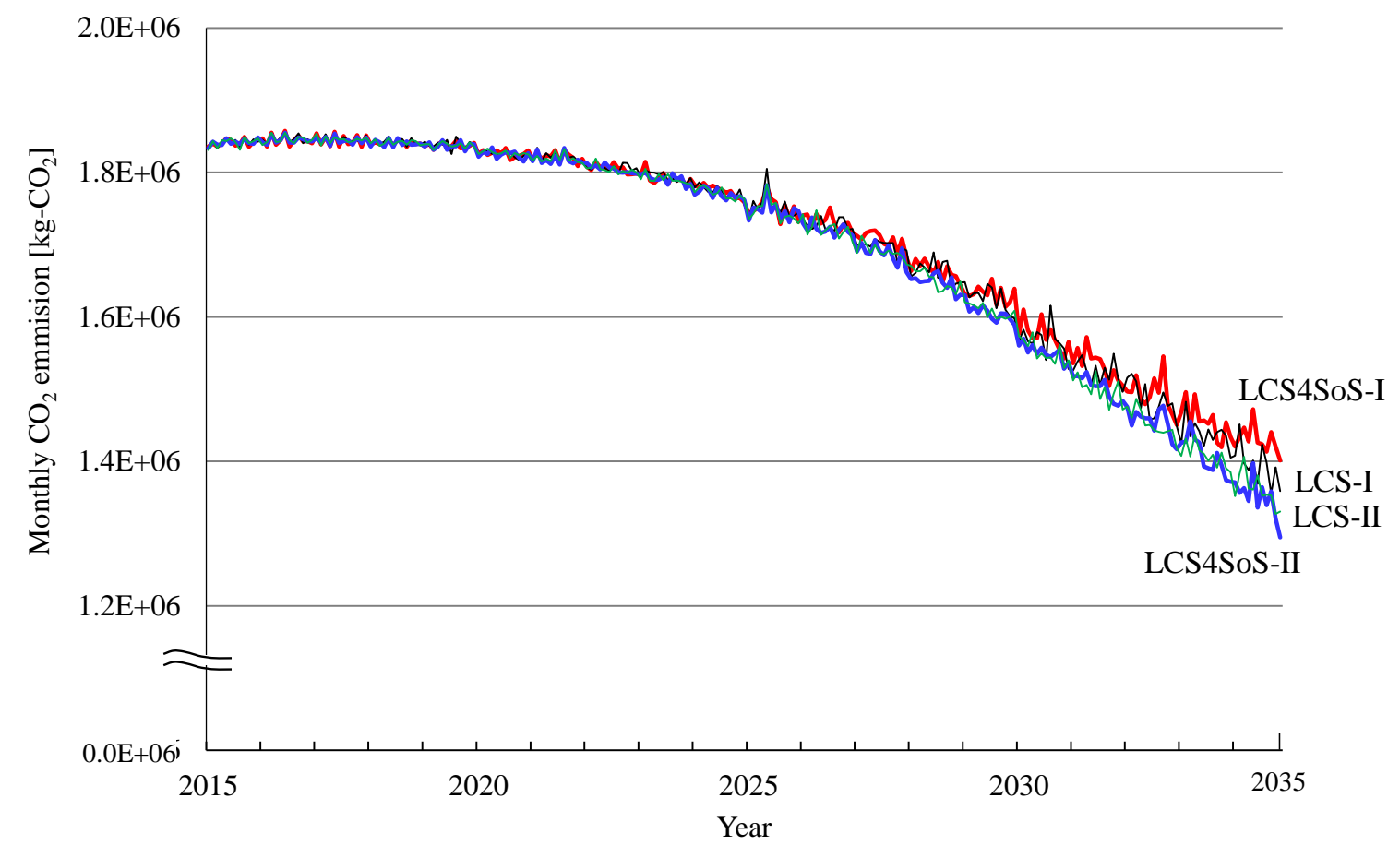

Figure 12: Comparison of carbon dioxide emissions between LCS4SoS and a simple aggregation of LCS outputs with the same overall evaluation boundary

Consideration of the rebound effect, which is defined as the effect in which changed behavior may offset part of the environmental gain, is important for achieving sustainability at system level [Hertwich, 2005]. With LCS4SoS, the environmental rebound effect can be estimated if a new technology spreads and generates 
an interaction between its own life cycle system and the existing one. In the case study, the estimation gaps between LCS4SoS-I and the simple summation of the LCS (LCS-I and LCS-II) in Figures 10-12 indicate a rebound effect. Through the case study, it was found that LCS4SoS can estimate the environmental effects of forming an SoS consisting of product life cycle systems under the various conditions.

\section{Discussion}

In this study, a new LCS methodology called LCS4SoS that is used to estimate the material flow and environmental load of an SoS consisting of product life cycle systems was proposed. This methodology makes it possible to quantify the change in material consumption and environmental burden, such as carbon dioxide emission, in the evaluation boundary caused by interactions among product life cycle systems. The originality of the LCS4SoS is in proposing how to model important system interactions in the context of product life cycle, thereby expanding the system boundary of calculation reasonably from a life cycle system of a single product family to one with multiple and different kinds of product life cycle systems. This is a breakthrough in the field of LCS study because using the proposed methodology increases the applicable target systems considerably. LCS4SoS is significant because it can support designing a quasi-steady-state system in which material inflow to the overall system, including an SoS, is reduced and stabilized [Kobayashi 2016]. This study does not replace previous studies about inverse manufacturing and industrial symbiosis but rather integrates them in a complementary manner. By using LCS4SoS, it is possible to evaluate an integrated system consisting of multiple inverse manufacturing and industrial symbiosis systems, which is more realistic than the systems considered in previous studies.

However, several limitations exist for LCS4SoS. Most of these limitations arise because LCS4SoS is based on traditional LCS techniques. First, traditional LCS is essentially based on the product and flows of parts related to product life cycle activity. It assumes that the process elements and product structure are well-defined and given, and this is also the case for LCS4SoS. The development of a simulation methodology for general SoSs is out of its scope. Second, traditional LCS evaluates the product and flows of parts from the environmental and economic standpoints at the business level, and this is the same for LCS4SoS. LCS4SoS cannot be applied at a national or global level, or from a social standpoint. Third, the proposed LCS4SoS does not explicitly 
handle market growth or contraction. In fact, product diffusion scenarios were given based on the existing product diffusion model in the case study. This is because traditional LCS does not have a mechanism to handle market growth. Fourth, although traditional LCS is useful for evaluating mass production or customized mass production in which many products are made and used, it is not well suited to evaluating complete order-made products, and LCS4SoS has the same limiting characteristics. For instance, power infrastructure systems consisting of electric power generators, transformers, and distribution stations have not yet been evaluated by LCS.

Topics for future work are as follows.

1) It is necessary to further consider how to reflect differing priorities for various standpoints with the LCS4SoS model, for instance, the standpoints of the company, the kinds of products, or the industrial sector. From the company's viewpoint, modeling cooperativeness and competitiveness among different companies should be prioritized. If the same kinds of product life cycle systems are modeled for different companies with business agreements, then the environmental and economic effectiveness of the common parts and standardization can be analyzed based on the LCS4SoS methodology. In the same way, the usefulness of collaborative production and a new business ecosystem can be analyzed. For this purpose, new modeling knowledge might be needed. However, when industrial symbiosis needs to be analyzed in a broader area, not a local area, each product life cycle system should be modeled region by region. Because geographic distribution is one of the characteristics of SoS [Maier 1996], this issue should also be considered. The above issues should also be considered from the viewpoint of the hierarchy of the LCS model.

2) A more sophisticated method for modeling interactions should be established. In the real world, interactions among product life cycle systems are generated and disappear unexpectedly. It is difficult and unrealistic to automatically estimate such dynamic generation and disappearances over a long term. Preferably, a simulation based on LCS4SoS would execute in the system operation and management phase when a somewhat likely interaction appears. The idea that LCS is carried out continuously after product release is a key part of the stock-based approach [Kobayashi 2016]. In this way, other new LCS 
methodologies, such as data-assimilated LCS (DA-LCS) [Fukushige et al. 2017], could be integrated with LCS4SoS.

3) A more-sophisticated method is required for selecting SoS system boundaries. The related issues are twofold. One is a procedural issue. Analytic approaches, such as minimal cut-off theory, cannot be used to set the system boundary of an SoS because material flows used for such analytic theories are obtained after LCS calculation. Only simulation approaches are applicable in such cases. In this study, we applied a cut-off concept in the field of LCA [Raynolds et al., 2000]. If a new appropriate method were to be proposed, it could be tried in application to LCS4SoS. The second is to select evaluation indicators for setting system boundaries. In this study, the cut-off decision was made based on the virgin copper consumption computed by the initial system model. This is because the increase of copper consumption is connected to EV being diffused in the real world [Kishita et al. 2012]. However, this indicator, namely, copper consumption, might not be appropriate from the viewpoint of comprehensiveness. For example, total material requirements (TMR) [Bringezu and Moriguchi 2002], which evaluates the direct and indirect resource flows comprehensively, could be applied in future work.

4) In this study, the demand scenario was given exogenously as product diffusion data by using existing models, such as the logistic curve model. However, total demand or total market capacity is changed by not only population and economic conditions but also by system interactions. An approach that combines an endogenous modeling method such as SD [Richardson 2011] and ABM [Macal and North 2010] on changes in demand with the proposed methodology is another future work.

5) An application for sharing businesses, such as car sharing or ride-sharing, is a future issue. Moreover, the effects of price change on system interactions should be studied. In this study, economic analysis using LCS4SoS was not shown. Because simulation results of these applications of LCS4SoS show the usefulness and validity of the methodology at the level of detailed system implementation, these will be reported at another opportunity. 


\section{Conclusions}

In this paper, a new LCS methodology called LCS4SoS was proposed. The contributions of this paper is summarized as threefold.

- The LCS4SoS methodology, which is based on traditional LCS techniques and a new interaction concept between product life cycle systems, was proposed for evaluating the environmental sustainability of an SoS consisting of product life cycle systems.

- A prototype system based on LCS4SoS was developed, and the usefulness of the proposed methodology was demonstrated through a case study applied to the prototype system.

- The limitations of LCS4SoS and areas for future work were discussed.

The ultimate goal of this study is to establish a methodology to find critical interactions for reducing and stabilizing material inflow to an overall system, and to design and manage these interactions appropriately. The LCS4SoS methodology must be improved in order to achieve this goal.

\section{Acknowledgements}

The authors are grateful to Dr. Hidenori Murata, Dr. Yuuki Matsuyama, Mr. Kazune Kawakami, and Mr. Taichi Morita, who studied related works in our laboratory. The authors would also like to thank Dr. Hitoshi Komoto of National Institute of Advanced Industrial Science and Technology (AIST) for valuable discussion about LCS4SoS.

\section{References}

[Alting and Legarth 1995] L. Alting. J. Legarth, Life cycle engineering and design, Annals of the CIRP, 44 (2) (1995) 569-580.

[Bass 1969] F. Bass, A new product growth for model consumer durables, Management Science, 15 (5) (1969) 215-227. 
[Benton and Shin 1998] W. Benton, H. Shin, Manufacturing planning and control: The evolution of MRP and JIT integration, European Journal of Operational Research, 110 (1998) 411-440.

[Bringezu and Moriguchi 2002] S. Bringezu and Y. Moriguchi, "Material flow analysis" in: A handbook of industrial ecology, R. Ayres, L. Ayres eds., Edward Elgar, 2002, pp. 79-90.

[CHAdeMO 2010] CHAdeMO Association, Specification, structure and setting of fast charging equipment, 2010, in Japanese.

[CHAdeMO 2017] CHAdeMO Association, https://www.chademo.com/products/chargers/, accessed in Sept. 15, 2017.

[Chertow 2000] M. Chertow, Industrial symbiosis: literature and taxonomy, Annu. Rev. Energy and Environment, 25 (2000) 313-337.

[Davis et al. 2009] C. Davis, I. Nikolic, G. Dijkema, Integration of life cycle assessment into agent-based modeling, 13-2 (2009), 306-324.

[Dumoulin et al 2016] F. Dumoulin, T. Wassenaar, A. Avadi, J. Paillat, A framework for accurately informing facilitated regional industrial symbioses on environmental consequences, Journal of Industrial Ecology, (2016) DOI: $10.1111 /$ jiec.12495.

[DeLaurentis and Ayyalasomayajula 2009] D. DeLaurentis, S. Ayyalasomayajula, Exploring the synergy between industrial ecology and system of systems to understand complexity, Journal of Industrial Ecology, 13 (2) (2009) 247-263.

[DoD 2008] United States Department of Defense (DoD), Systems engineering guide for systems of systems, 2008.

[EC 2015] The European Commission, Closing the loop - An EU action plan for the circular economy, 2015.

[Ekvall and Weidema 2004] T. Ekvall, B. Weidema, System boundaries and input data in consequential life cycle inventory analysis, Int. J. LCA, 9 (3) (2004) 161-171.

[Ellen MacArthur Foundation 2013] The Ellen MacArthur Foundation, Toward the circular economy, 2013.

[Finnveden et al. 2009] G. Finnveden, M. Hauschild, T. Ekvall, J. Guine'e, R. Heijungs, S. Hellweg, A. Koehler, D. Pennington, S. Suh, Recent development in life cycle assessment, J. Env. Management, 91 (2009), 1-21. 
[Florent and Enrico 2015] Q. Florent, B. Enrico, Combining agent-based modeling and life cycle assessment for the evaluation of mobility policies, Environmental Science \& Technology, 49 (2015), 1744-1751.

[Forrester 2007] J. Forrester, System dynamics - a personal view of the first fifty years, Syst Dyn Rev, 23 (23) (2007) 345-358.

[Frosh and Gallopoulos 1989] R. Frosh, N. Gallopoulos, Strategies for manufacturing, Scientific American, 261, (1989) 144-152.

[Fukushige et al. 2017] S. Fukushige, M. Nishioka, H. Kobayashi, Data-assimilated lifecycle simulation for adaptive product lifecycle management, CIRP Annals - Manufacturing Technology, 66-1, (2017), 37-40.

[Garetti et al. 2012] M. Garetti, P. Rosa, S. Terzi, Life cycle simulation for the design of product-service systems, Computers in Industry, 63 (2012), 361-369.

[Gorod et al 2008] A. Gorod, B. Sauser, J. Boardman, System-of-systems engineering management: A review of modern history and a path forward, IEEE Systems Journal, 2 (4) (2008) 484-499.

[Graedel and van der Voet 2010] T. Graedel, E. van der Voet, (eds.), Linkages of sustainability, The MIT Press, Cambridge, 2010.

[Graedel 2011] T. Graedel, The prospects for urban mining, The Bridge, 41 (1) (2011) 43-50.

[Guide Jr and Li 2010] V. Guide Jr., J. Li, The potential for cannibalization of new products sales by remanufactured products, Decision Sciences, 41 (3) (2010) 547-572.

[Hauschild et al. 2017] M. Hauschild, C. Herrmann, S. Kara, An integrated framework for life cycle engineering, Procedia CIRP, 61 (2017) 2-9.

[Hertwich 2005] E. Hertwich, Consumption and the rebound effect - An industrial ecology perspective -, Journal of Industrial Ecology, 9 (1-2) (2005) 85-98.

[ISO 1997] International Organization for Standardization, ISO 14040, Environmental management -Life cycle assessment - Principles and framework, 1997.

[Jamshidi 2009] M. Jamshidi eds., System of systems engineering, Wiley, 2009.

[Kimura and Suzuki 1996] F. Kimura, H. Suzuki, Product life cycle modelling for inverse manufacturing, Proceedings of the PROLAMAT '95, Chapman \& Hall, Ltd., 1996, 80-89. 
[Kishita et al. 2012] Y. Kishita, , Y. Inoue, H. Kobayashi, S. Fukushige, Y. Umeda, Estimation of long-term copper demand based on sustainability scenarios: A challenge to sustainable manufacturing industry, Proceedings of the ASME 2012 Design Engineering Technical Conferences, Chicago, 2012, DETC2012-70695. [Kumazawa and Kobayashi 2006] T. Kumazawa, H. Kobayashi, A simulation system to support the establishment of circulated business, Adv. Eng. Inf., 20 (2) (2006) 127-136.

[Kobayashi 2003] H. Kobayashi, Product life cycle planning, Ohmusya Ltd., 2003, in Japanese.

[Kobayashi and Kumazawa 2005] H. Kobayashi, T. Kumazawa, A simulation-based decision support methodology for reuse business, Proceedings of the 4th International Symposium on Environmentally Conscious Design and Inverse Manufacturing (EcoDesign’05), Tokyo, 2005, 3A-1-2F.

[Kobayashi 2005] H. Kobayashi, Strategic evolution of eco-products: A life cycle planning methodology, Research in Engineering Design, 16, (1-2), (2005), 1-16.

[Kobayashi 2016] H. Kobayashi, A Framework of Stock-based System Design and Management toward a Steady-state Society, Proceedings of the Electronics Going Green+ (EGG2016+), Berlin, 2016.

[Komiyama and Kraines 2008] H. Komiyama, S. Kraines, Vision 2050: Roadmap for a sustainable Earth, Springer, Tokyo, 2008.

[Macal and North 2010] C. Macal, M. North, Tutorial on agent-based modeling and simulation, Journal of Simulation 4 (2010), 151-162.

[Maier 1996] M. Maier, Architecting principles for systems-of-systems, Proceedings of the INCOSE, 6 (1) (1996) 565-573.

[NEDO 2008] New Energy and Industrial Technology Development Organization (NEDO), Mizuho Information \& Research Institute Inc., Life cycle evaluation of stationary fuel cell system and fuel cell vehicle, The final report of NEDO project, 2008.

[NEDO 2009] New Energy and Industrial Technology Development Organization (NEDO), Mizuho Information \& Research Institute Inc., Life cycle evaluation of photovoltaic system, The final report of NEDO project, 2009.

[NIST 2014] National Institute of Standards and Technology (NIST), NIST framework and roadmap for smart grid interoperability standards, Release 3.0, 2014. 
[OECD 2015] Organization for Economic Co-operation and Development (OECD), How's life? 2015: measuring well-being, 2015.

[Raynolds et al. 2000] M. Raynolds, R. Fraser, D. Checkel, The relative mass-energy-economic (RMEE) method for system boundary selection, Part 1: A means to systematically and quantitatively select LCA boundaries, Int. J. LCA, 5 (1) (2000) 37-46.

[Richardson 2011] G. Richirdson, Reflections on the foundations of system dynamics, System Dynamics Review, 27 (3) (2011) 219-243.

[Seendra et al 2007] C. Seendra, X. Gabarrell, T. Vicent, Material flow analysis adapted to an industrial area, J. Clean. Prod., 15 (2007) 1706-1715.

[Steffen et al 2015] W. Steffen, K. Richardson, J. Rockström, S. Cornell, I. Fetzer, E. Bennett, R. Biggs, S. Carpenter, W. de Vries, C. de Wit, C. Folke, D. Gerten, J. Heinke, G. Mace, L. Persson, V. Ramanathan, B. Reyers, S.Sörlin, Planetary boundaries: Guiding human development on a changing planet. Science, 347 (6223) (2015), 736-746.

[Takata and Kimura 2003] S. Takata, T. Kimura, Life cycle simulation system for life cycle process planning, CIRP Annals - Manufacturing Technology, 52 (1) (2003) 37-40.

[Tillnvan et al 1994] A. Tillnvan, T. Ekvall, T. Rydberg, Choice of system boundaries in life cycle assessment, J. Clean. Prod., 2 (1) (1994), 21-29.

[Umeda et al 2000] Y. Umeda, A. Nonomura, T. Tomiyama, Study on life-cycle design for the post mass production paradigm, AIEDAM, 14 (2000) 149-161.

[UN 2015] United Nations, Sustainable Development Goals, United Nations Sustainable Development, 2015. [UNEP 2012] United Nations Environmental Programme, Global Environmental Outlook 5, 2012.

[UNEP 2016] United Nations Environmental Programme, Global material flows and resource productivity, 2016.

[Velenturf 2016] A. Velenturf, Promoting industrial symbiosis: empirical observation of low-carbon innovations in the Hember region, UK, J. Clean. Prod. 128 (2016) 116-130.

[Weck et al 2011] O. Weck, D. Roos, C. Magee, Engineering systems, The MIT Press, 2011. 
[Wenzel et al 1997] H. Wenzel, M. Hauschild, L. Alting, Environmental assessment of products, Vol. 1, Chapman\& Hall, London, 1997.

[Zeigler et al 2000] B. Zeigle, H. Praehofer, T. Kim, Theory of modeling and simulation, $2^{\text {nd }}$ edition, Academic Press, 2000. 